\title{
DISINFORMATION AS A THREAT TO THE QUALITY OF CONTEMPORARY INFORMATION
}

\author{
Yuliia TURCHENKO*, Kira HORIACHEVA*, Oleksandr DZHUS*, \\ Oleh KOLISNYK**
}

\author{
*"Taras Shevchenko" National University of Kyiv, Ukraine \\ **National Defence University of Ukraine, Ukraine \\ horyachevakira@gmail.com
}

\begin{abstract}
Due to the intensification of local conflicts in the world, ensuring the quality of information is a pressing problem, which is complicated by the lack of a unified methodological framework that allows for an adequate assessment of information threats. Current methods often do not take into account the nature of the interaction of various negative factors and give an assessment only on a qualitative level. The difficulty of analyzing risks in the information sphere lies in the fact that in order to achieve adequate assessments it is necessary to take into account a large number of factors that are in a complex dependence on one another. This article describes the negative influence of disinformation on social and political processes in the state. For the study we use the experience of the United States and Great Britain during significant political events, the experience of information operations in social networks. We also agree that there are many threats to the quality of information in the modern world. One of these threats is disinformation, which inevitably manipulates reality and facts in order to cause harm or financial gain. The article states that disinformation breeds discontent, distrust of state institutions, undermines the legitimacy of power, generates unwarranted tension in the society, as well as curtails public debate and threatens the quality of information.
\end{abstract}

Keywords: disinformation, fake news, quality of information, propaganda, threat

\section{Introduction}

The influence of the Internet on the dissemination of information and interpersonal communication is constantly growing.

On this basis, the quality of information that is distributed through the digital media is directly dependent on the quality of the source of information and regulatory mechanisms of the state, as it can have negative socio-political consequences.

According to Moore (2016) the "civic power" of tech giants extends to the processes governing the formation and exchange of opinions as well as the establishment of reputation and popularity [1].
Researchers N. Allcott and M. Gentzkow (2017) conducted research on the impact of social media and fake news during elections, suggesting that digital media use manipulative psychometrics and are responsible for the spread of Fake News. And therefore, have to do with disinformation and is a threat to the quality of information in general [2].

Moreover, D. Tambini (2018) in his study "Social Media Power and Election Legitimacy" concludes that misinformation and manipulative technologies undermine electoral integrity and transparency [3]. 
2. Disinformation in the Modern World: Propaganda and Fake News

In today's world, the media themselves have changed, as have the methods of distributing information. Disinformation and propaganda have always existed, so there has always been a threat to the quality of information. In today's world, with the advent of the Internet and the development of digital media, spreading disinformation has become faster and easier.

\subsection{Fake News}

A great deal of the fake news we encounter every day overlaps with other phenomena such as misinformation. Following M. David and J. Laser (2018) disinformation is false or misleading information and disinformation is false information that is intentionally spread to deceive people [4].

People spend a lot of time on the Internet and use it as a way to get the latest news and information. Thus, the importance of the Internet and digital media in spreading fake news cannot be underestimated.

It is worth noting that disinformation may have the ultimate goal not only to benefit from advertising, but also to have a destructive impact on the socio-political environment.

Consequently, the threat to the quality of disseminated information can be the cause of destructive processes in the state.

\section{The need for information monitoring and regulatory mechanisms of the state}

The existing information disorder and manifestations of disinformation force information sites to check information in the news cycle and facts involving a large number of employees. However, human verification is a very complicated and timeconsuming process. Moreover, the subjective interpretation of information may be limited by the personal experience of the verifier [5]. Conroy et al in their study proposed the use of machine algorithms to facilitate the detection of false information [6].
Following D. Maria and other scholars in their study "Fake News" Is Not Simply False Information: A Concept Explication and Taxonomy of Online Content" identify seven different types of online content under the label "fake news" (fake news, polarized content, satire, misrepresentation, commentary, persuasive information and citizen journalism). This fake news is contrasted with "real news" by introducing a taxonomy of operational indicators in four domains such as - message, source, structure and network [7]. This system according to the authors of the study can help explain the nature of online news information.

The information field is very dynamic and in crisis situations the scale of the fabricated problem can be irreversible. In this context, machine solutions seem inevitable to address the scale and speed with which they are created and disseminated, especially during elections, disasters, crises and other developing events. Consequently, the need to monitor disinformation, to develop effective algorithms for detecting fabricated news should be supported by all participants in the information field, as well as by state structures responsible for information security.

\section{Political Disinformation}

Research in the field of political disinformation is constantly growing. New approaches to managing and monitoring political disinformation are especially important because information disorder can threaten the economic stability of a state. This was clearly demonstrated by the manipulation of information during the Covid-19 pandemic. Moreover, strategic planning of disinformation is necessary to protect the interests of the state. Disinformation, as a threat to the quality of information, is an important and complex social problem because it is interdisciplinary in nature. The state needs to take on a regulatory function and develop 
the necessary mechanisms for managing digital media.

Recent important socio-political events, such as the Covid-19 pandemic, the U.S. presidential elections in 2020, 2016, and the Brexit vote in the UK, have shown the need for continued research in the field of political communications. Although there is a lot of research on political disinformation.

\subsection{Political disinformation on Twitter and Facebook}

Discussions about the need to respond to disinformation became relevant during the 2016 Brexit referendum campaign and after the U.S. presidential election. Since then, the spreading of false information on online platforms such as Facebook and Twitter has been actively discussed. While this phenomenon is not new, the relevant aspect in this context is that online platforms contribute to the rapid and global spread of news, causing the "viralization" of content. Thus, the expression "fake news" has become quite popular.

Following Allcott and Gentzkow (2017), fake news is defined as news that is "intentionally and reliably false and likely to mislead readers [2].

\subsection{Government Action}

In recent years, governments are increasingly thinking about strategic planning to counter disinformation. Because the level of manipulation of public opinion that manifests itself in fake news can be threatening.

States are concerned about the steady growth of fake news and are aware of the need to actively combat fake news. Various state agencies are now creating services to refute stories they believe to be false. Government agencies are also considering introducing rules and leverage for sites that publish misinformation.

These rules would include steps to combat misinformation. Government leverage mechanisms include suspending bots/suspicious accounts, adding features that allow users to report fake news, and involving more personnel to monitor and enforce information security.

\section{Conclusions}

The results of our study are partly in line with received wisdom and existing research. In recent years there has been an explosion of research on disinformation. This work is leading to important insights into where disinformation arises, how it spreads, and why it is believed. However, the widespread attention given to this topic exposes it to the risk of dissipation. Much more research is needed to understand the complex and difficult problem of disinformation, and we hope that our research will lead to exciting new topics that will help address this important sociopolitical issue.

\section{References List}

[1] Moore M. Tech giants and civic PowerBook. Centre for the Study of Media, Communication and Power; 2016. p. 92.

[2] Allcott H., Gentzkow M. Social Media and Fake News in the 2016 Election. Journal of Economic Perspectives, Vol. 31(2). 2017. 211-36 p. DOI: 10.1257/jep.31.2.211.

[3] Tambini D. Social media power and election legitimacy. Digital dominance: the power of Google, Amazon, Facebook, and Apple. Oxford University Press, NY. 2018. pp. $265-$ 293. ISBN 9780190845117.

[4] David M. J. Lazer, et al. The Science of Fake News. Science. Vol. 359, Issue 6380. 2018. pp. 1094-1096.

[5] Vorhies W. Using algorithms to detect fake news: The state of the art. 2017. Available from: https://www.datasciencecentral.com/profiles/blogs/using-algorithms-to-detectfakenews-the-state-of-the-art?. 
[6] Conroy, N. J., Rubin, V. L., \& Chen, Y. Automatic deception detection: Methods for finding fake news. Proceedings of the Association for Information Science and Technology, 52. 2015. pp. 1-4. doi:10.1002/pra2.2015.145052010082.

[7] Molina M. D., Sundar S. S., Le T., Lee D. "Fake News" Is Not Simply False Information: A Concept Explication and Taxonomy of Online Content. American Behavioral Scientist, 65(2). 2021. pp. 180-212. Available from: https://doi.org/10.1177/0002764219878224. 